\title{
Analysis of Automobile Shaft for Optimizing Weight by Using Fem
}

\author{
Ravi Prakash \\ M. Tech. Scholar \\ NRI Institute of Information Science and Technology \\ Bhopal, India \\ raviprakash058@gmail.com
}

\author{
Yogesh Mishra \\ Professor \\ NRI Institute of Information Science and Technology \\ Bhopal, India \\ ymishra11@gmail.com
}

\begin{abstract}
Composites have been increasingly used in many engineering fields. Polymer composites are now widely used to build automotive components due to their exceptional rigidity and strength properties. Composite shafts for automotive applications are among the most recent research areas. A weight reduction can be achieved mainly with the introduction of a better material. The conventional system uses a metal shaft and has inherent limitations such as weight, corrosion, elasticity, vibration, storage and manufacturing problems increase with increasing shaft diameter. Advanced composites offer the opportunity to improve the transmission shaft by reducing weight, bearing load, misalignment and life cycle costs through the use of strategic materials, increasing the properties of resistance to fatigue, flexibility and vibration damping. The objective is the design and analysis of composite hollow shafts made of low density carbon fiber reinforced plastic (CFRP) for motor vehicles. And To investigate the vibrational effect of propeller shaft at different mode condition using FEA by ANSYS 18.2. In this result are the total weight of carbon fiber shaft is reduce. The total weight of the carbon fiber shaft is $2.6 \mathrm{~kg}$ is less then to previous material. And the previous study material of weight is $3.2 \mathrm{~kg}$.
\end{abstract}

\section{INTRODUCTION}

Composite materials can be defined as a macroscopic combination of two or more materials with a recognizable interface between them. Composite materials generally have a fibrous or particle phase that is more rigid and more resistant than the continuous phase. Today's people use composites for a variety of applications in various fields, some in aerospace, automotive, construction, and so on. In automotive applications, people use car door trim composites, in engine hoods, the transmission system in the form of composite fiberglass drive shafts.

\section{Drive Shaft}

The term "transmission shaft" refers to a tree used to transmit movement from one point to another. In the car, the propeller shaft is the connection between the transmission and the rear axle.

A transmission shaft is a mechanical component for the transmission of torque and rotation, normally used to connect other components. A power unit that cannot be connected directly due to distance or related needs. To allow movement between them. The transmission shafts are subjected to torsional and shear stresses such as torque supports which correspond to the difference between the input torque and the load. They must therefore be sturdy enough to support the load while avoiding additional weight because it would increase their inertia. To account for variations in alignment and spacing between input and output components, transmission shafts often include one or more universal joints, dog couplings or flap seals and sometimes a grooved joint or a prism.

\section{Applications of FEA}

- Structural engineering (analysis of frames, trusses, bridges etc.).

- Aircraft engineering (analysis of aero plane wings, different parts of missiles and Rockets).

- Heat engineering (analysis on temperature distribution, heat flux etc.). 
- Hydraulic and hydrodynamic engineering (analysis of viscous flow, potential and

Boundary layer flows).

\section{LITERATURE REVIEW}

D Sarath Kumar et al. [1] this article presents the material sciences on which a great deal of research has been conducted in recent years. This is due to the scarcity of raw materials needed for production. In the technical field, the availability of the raw material and the cost of the raw material are the main factors in the choice of the product to be manufactured. On the other hand, the physical and mechanical properties of the material must be analyzed before the start of production. This is because the design has been preserved and the promises of the product have been fulfilled. The car is also an area where new innovations and technologies are born every day. In this work, a split helix tree is modeled and analyzed using the FEA analysis with the ANSYS software.

B.James Prasad Rao et al. [2] this article is dedicated to studies on carbon-reinforced plastic (CFRP) and composite FRP hollow shafts for motor vehicles. The failure analysis was performed using the maximum stress criteria and it was found that the fault torque is much higher than the nominal torque. For a precise design solution, the transmission shaft was analyzed using FEM techniques (ANSYS software). To verify all the failure modes, a linear static analysis, an analysis of the vibration eigenvalue, a distortion analysis and a harmonic analysis were performed.

Mohammad Reza Khoshravan et al. [3] this article presents the design methods and vibration analysis of compound drive shafts. In the design of compound shafts, some parameters are examined such as the critical speed, the static torque and the adhesive seals. A cordon shaft is not limited to vehicles, but can be used in many transmission applications. In this publication, however, the goal is to replace a metal transmission shaft with a two-part transmission shaft. The construction of a compound crankshaft is divided into two main sections: the construction of the composite shaft and the construction of the joints.

Dattatray S. Ghorpade et al. [4] this work focuses on the experimental study of the performance of conventional steel propeller shafts with the epoxy-carbon compound drive shaft. A propulsion shaft for a rear-wheel drive vehicle was built using carbon epoxy composite materials. The replacement of conventional metal structures with composite structures has many advantages due to the higher specific rigidity and greater specific strength of the composites. A composite carbon-epoxy composite shaft is tested using a torque tester.

\section{OBJECTIVES}

- To enhance the shear stress shaft by changing material use in construction of the propeller shaft to obtained the reduce the weight in the previous study.

- To design the parallel shaft with the suitable material which minimize the maximum stress level compare to the previous study.

- To investigate the vibrational effect of propeller shaft at different mode condition.

\section{PROBLEM OF FORMULATION}

1. Almost all automobiles (at least those which correspond to design with rear wheel drive and front engine installation) have transmission shafts.

2. The weight reduction of the drive shaft can have a certain role in the general weight reduction of the vehicle and is a highly desirable goal, if it can be achieved without increase in cost and decrease in quality and reliability.

3. It is possible to achieve design of composite drive shaft with less weight to increase the first natural frequency of the shaft.

\section{METHODOLOGY}

\section{Analysis of Shaft by Application of FEM under Static Conditions}

The static behavior analysis with the ANSYS 18.2 software was performed on the shaft of a land rover. The above analysis is performed for loads including, Modeling and analysis of the static behavior of the wave take place in a concrete case according to a defined procedure, carried out in the following phases:

a. Modeling of the shaft;

b. Discretization of the geometric model;

c. Discretization of the geometric model through the network of finite elements;

d. Definition of boundary conditions and load; 
e. Processing - resolution of the general mathematical model; is

f. Presentation of the calculation results in numerical and graphic form.

By graphically representing the status of the model analyzed, the following representations are provided: Contour (which shows changes in shifts and characteristic stresses throughout the model, with the boundaries between adjacent areas indicated by solid lines);

g. the deformed model under load.

c. Reaction forces on the model.

\section{Modeling of the shaft}

The construction of the database on the shaft allows the formation of a discrete model in which it is possible to define different loads and constraints, thus shortening the processing time and the analysis time itself. In this particular case, the creation of the finite element network is carried out with tetrahedral elements, which allows us to describe the rotational shape of the observed model quite well. Using the volume modeling method, the shaft model is constructed from the computer model of the volume model, which is executed by rotating the profile around the symmetry axes (sweep). The selected finite elements are joined to the nodes that represent links to imaginary nodes. For each node in which finite elements are connected, an equation of elastic forces is defined, which defines the relationship between stress and deformation. The balance of the finite elements is analogous to the balancing of the rods in a reticular beam. The constraints and the external limits are included in the equations for the finite elements on the contour of the form and, by solving the system of these equations, we obtain displacement values, i.e. deformations and "Von Misses" constraints in all the nodes. After the calculation, the values of the extreme constraints, or the extension of the displacement of the nodes on the y axis, are displayed graphically and numerically.

Based on the ANSYS software system capacity analysis for this particular wave case, it was concluded that the simplest way to model is to rotate the profile of the upper half of the axial section around the axes. $360^{\circ}$ rotation. Compared to the actual shape of the wave, the modeling was performed to omit edges, grooves and rays. However, in a subsequent phase of the creation of the matrix of finite elements, due to computational problems, a grouping of the selected contours was carried out, on the basis of which a simplified profile was obtained, which is represented in Fig. with the representation of the coordinate points of the given contour.

\section{Modeling And Finite Element Analysis of a Shaft}

A system seminar used for pre-editing, post-editing and post-processing. The properties of the shaft assembly material are the same because the steel shaft structure was selected in the ANSYS 18.2 metal library. The boundary conditions are applied to the tree and the finite element model is used to calculate the forms of deformation, deformation, frequency and mode in the component set using the ANSYS 18.2 software.

\section{Defining Boundary Conditions and Load}

In the first case of undulating load under radial force, the influence of the weight of the wave that is of gravity was also taken into consideration.

In the second case of shaft loading, the shaft analyzed in the left front section receives the torque from the shaft of the electric motor through the seal and transmits it to the turbine housing. During power transmission, the shaft is subjected to a torque at the connection point.

The shaft volume model is distributed linearly with respect to the $\mathrm{X}$ axis, while the linear springs are distributed conically on the pellet inclination points. The boundary conditions of the linear spring should meet the following requirements:

- Limited displacement of the knots in the elastic supports on the joint along the edge of the wave, except in the axial direction.

- Limited movement of the knots in the elastic supports at the end of the elastic springs.

\section{Preparation of model:}

A Shaft model is prepared in Ansys 


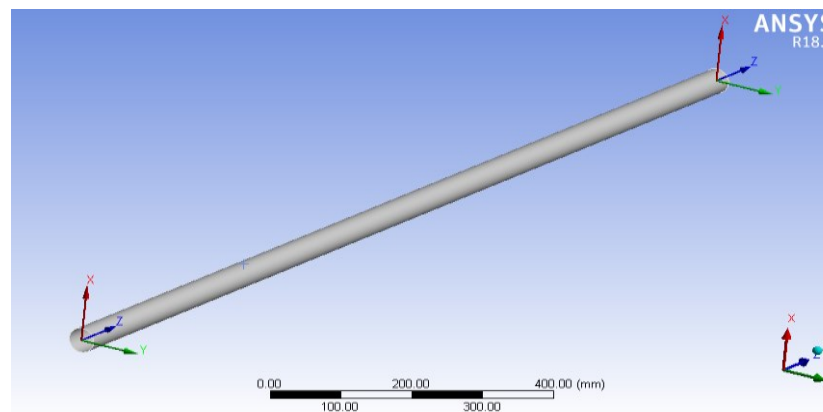

Figure 1: shaft model in ANSYS

\section{Steps of Working}

Step 1: Collecting information and data related to shaft.

Step 2: A fully parametric model of the composite shaft for both cases are created in Ansys.

Step 3: Model obtained in Step 2 is analyzed using ANSYS 18.2.

Step 4: Finally, we compare the results obtained from ANSYS

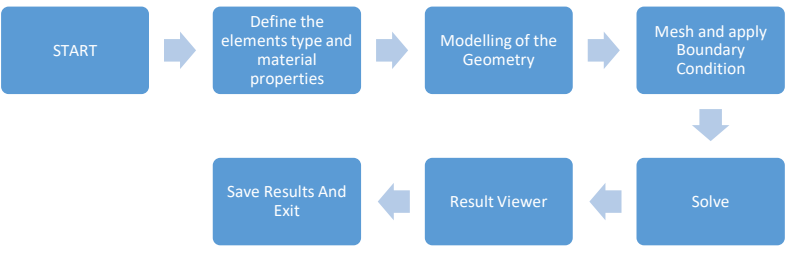

Figure 2: Setup of working

\section{Finite elements analysis}

Finite elements analysis is a branch of fluid mechanics that uses numerical analysis and data structures to solve and analyze problems that involve solid structure. For the present work ANSYS 18.2 software used.

\section{ANSYS Capabilities:}

In finite element analysis ANSYS software is used that helps engineers for performing the following tasks:

- To build computer prototype, components, transfer shaft models of structures in a system products.

- Enhances the profile of structural member with shape optimization.
- Physical responses, such as stress levels, temperature distributions, or electromagnetic field scan be studied.

- To reduce production costs optimization of design is done early in the development process.

- Testing of prototypes is done in environments where it otherwise would be undesirable or impossible (for example, biomedical applications).

Graphical user interface (GUI) in ANSYS gives users an easy, interactive approach to documentation, program functions, commands, and reference material. To navigate through the ANSYS program an intuitive menu system is used by users. Input data can be given using a mouse, a keyboard, or a combination of both.

\section{Steps of ANSYS Analysis}

The different analysis steps involved in ANSYS are mentioned below.

\section{[1] PREPROCESSOR}

The model setup is basically done in preprocessor. The different steps in pre-processing are

- $\quad$ Build the model

- Define materials

- Generation of element mesh.

\section{[2] BUILDING THE MODEL}

- Creating a solid model with in Ansys.

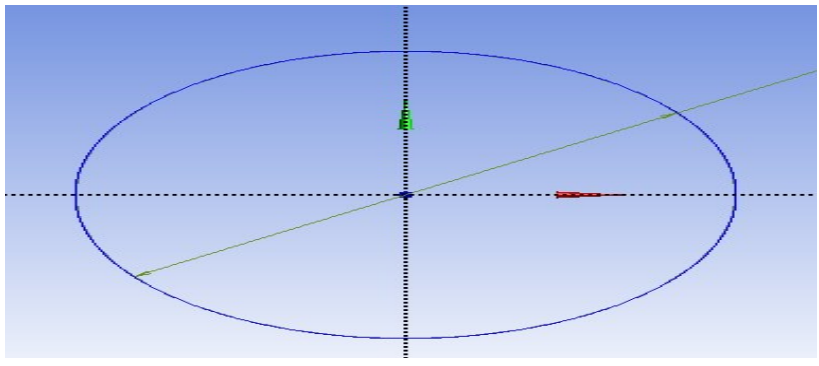

Figure 3: Front view shaft model prepared in Ansys (previous shaft model)

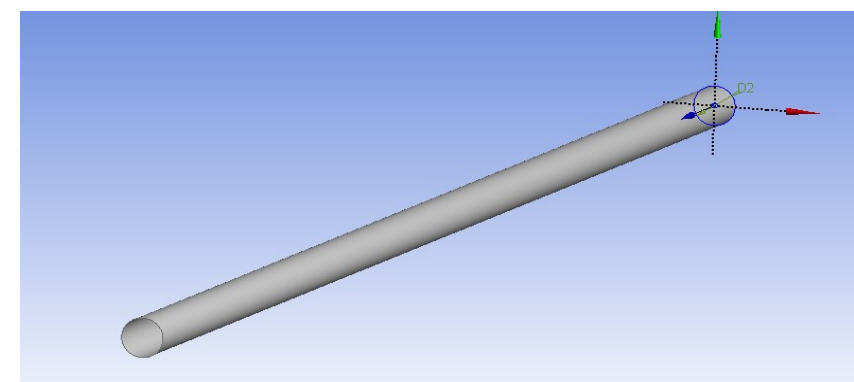


Figure 4: Side view with specify Diameter shaft model prepared in Ansys (conventional model)

\section{[3] Design Model for Analysis.}

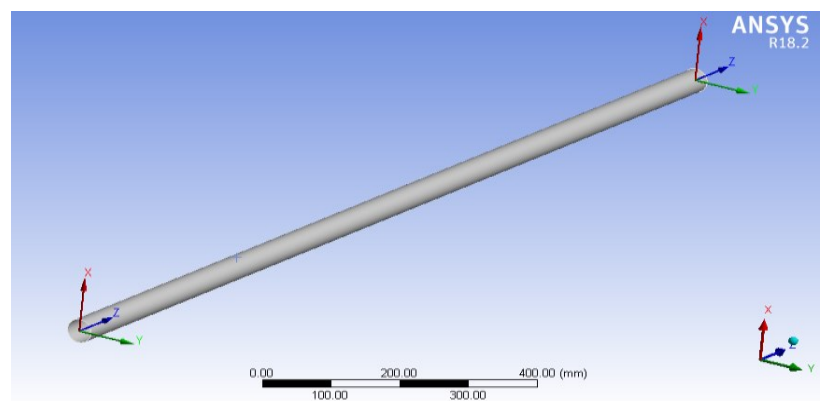

Figure 5: Side view shaft model prepared in Ansys (conventional model)

\section{MESHING}

The mesh created in this work is shown in figure No 4.6. The total Node is generated $2726 \&$ Total No. of Elements is 2686 , it is clear from the mesh geometry the node numbers and element numbers are almost seven in digit which show that the mesh is very fine because the result accuracy depends on the mesh quality

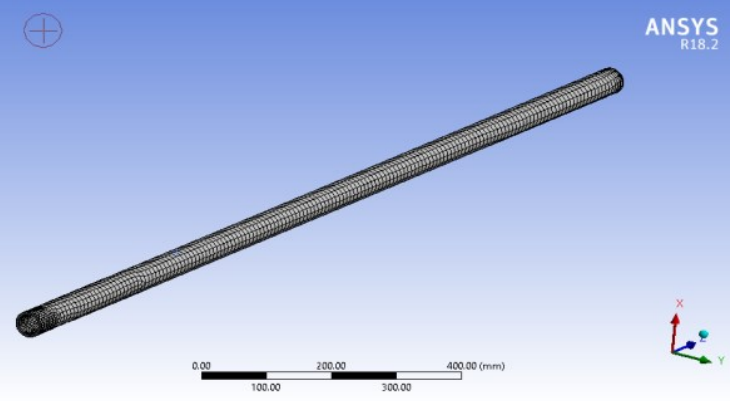

Figure 6: Meshing: Total No. of Nodes: 2726 \& Total No. elements: 2686

\section{DEFINING MATERIAL PROPERTIES}

$>\mathrm{HM}$ carbon properties

\begin{tabular}{|l|l|}
\hline Properties & Value \\
\hline Density $\left(\mathrm{kg} / \mathrm{m}^{\wedge} 3\right)$ & $1600 \mathrm{~kg} / \mathrm{m} 3$ \\
\hline Elastic modulus (pa) & $1.9 \mathrm{e}+011$ \\
\hline Poisson ratio & 0.3 \\
\hline
\end{tabular}

Table 1. - HM carbon Properties
Carbon low density properties

\begin{tabular}{|l|l|}
\hline Properties & \multicolumn{1}{l|}{ Values } \\
\hline Density $\left(\mathrm{kg} / \mathrm{m}^{\wedge} 3\right)$ & $1298 \mathrm{~kg} / \mathrm{m} 3$ \\
\hline $\begin{array}{l}\text { Elastic modulus } \\
\text { (pa) }\end{array}$ & $1.13 \mathrm{e}+8$ \\
\hline Poisson ratio & 0.32 \\
\hline $\begin{array}{l}\text { Yield strength } \\
\text { (N/m2 ) }\end{array}$ & $8.3 \mathrm{e} 8$ \\
\hline
\end{tabular}

Table 2:- Carbon Properties

\begin{tabular}{|r|c|}
\hline \multicolumn{2}{|c|}{ Bounding Box } \\
\hline Length X & $40 . \mathrm{mm}$ \\
\hline Length Y & $40 . \mathrm{mm}$ \\
\hline Length Z & $1750 . \mathrm{mm}$ \\
\hline Properties \\
\hline Volume & $1.0468 \mathrm{e}+006 \mathrm{~mm}^{3}$ \\
\hline Mass & $3.245 \mathrm{~kg}$ \\
\hline Centroid X & $6.4791 \mathrm{e}-016 \mathrm{~mm}$ \\
\hline Centroid Y & $-7.154 \mathrm{e}-016 \mathrm{~mm}$ \\
\hline Centroid Z & $875 . \mathrm{mm}$ \\
\hline Moment of Inertia Ip1 & $8.2775 \mathrm{e}+005 \mathrm{~kg} \cdot \mathrm{mm}^{2}$ \\
\hline Moment of Inertia Ip2 & $8.2775 \mathrm{e}+005 \mathrm{~kg} \cdot \mathrm{mm}^{2}$ \\
\hline Moment of Inertia Ip3 & $1289.8 \mathrm{~kg} \cdot \mathrm{mm}^{2}$ \\
\hline Surface Area(approx.) & $2.1991 \mathrm{e}+005 \mathrm{~mm}^{2}$ \\
\hline
\end{tabular}

Table 3 conventional material weight

\begin{tabular}{|r|c|}
\hline \multicolumn{2}{|c|}{ Bounding Box } \\
\hline Length X & $40 . \mathrm{mm}$ \\
\hline Length $\mathrm{Y}$ & $40 . \mathrm{mm}$ \\
\hline Length Z & $1750 . \mathrm{mm}$ \\
\hline Properties \\
\hline Volume & $1.0468 \mathrm{e}+006 \mathrm{~mm}^{\mathrm{s}}$ \\
\hline Mass & $2.6169 \mathrm{~kg}$ \\
\hline Centroid X & $6.4791 \mathrm{e}-016 \mathrm{~mm}$ \\
\hline Centroid Y & $-7.154 \mathrm{e}-016 \mathrm{~mm}$ \\
\hline Centroid Z & $875 . \mathrm{mm}$ \\
\hline Moment of Inertia Ip1 & $6.6754 \mathrm{e}+005 \mathrm{~kg} \cdot \mathrm{mm}^{2}$ \\
\hline Moment of Inertia Ip2 & $6.6754 \mathrm{e}+005 \mathrm{~kg} \cdot \mathrm{mm}^{2}$ \\
\hline Moment of Inertia Ip3 & $1040.2 \mathrm{~kg} \cdot \mathrm{mm}^{2}$ \\
\hline Surface Area(approx.) & $2.1991 \mathrm{e}+005 \mathrm{~mm}^{2}$ \\
\hline
\end{tabular}

Table 4 proposed material weight 


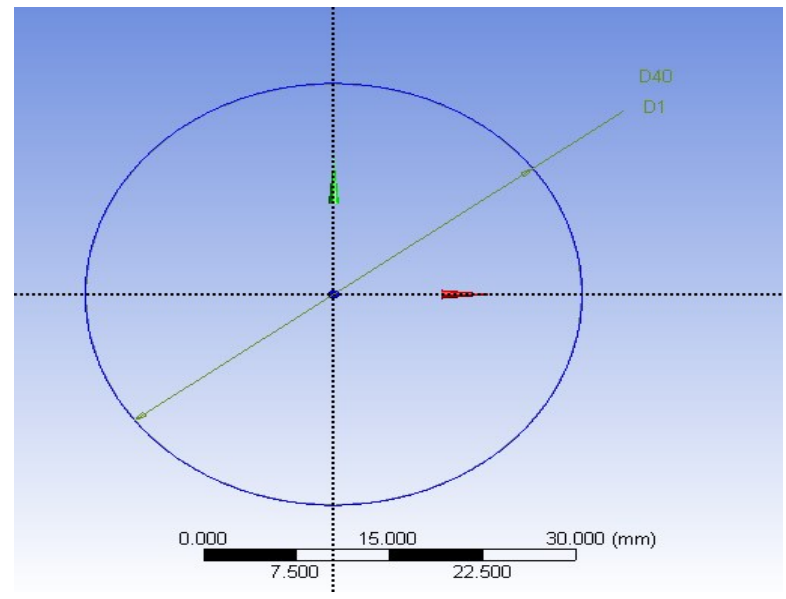

Figure 7 front views with dimension of shaft

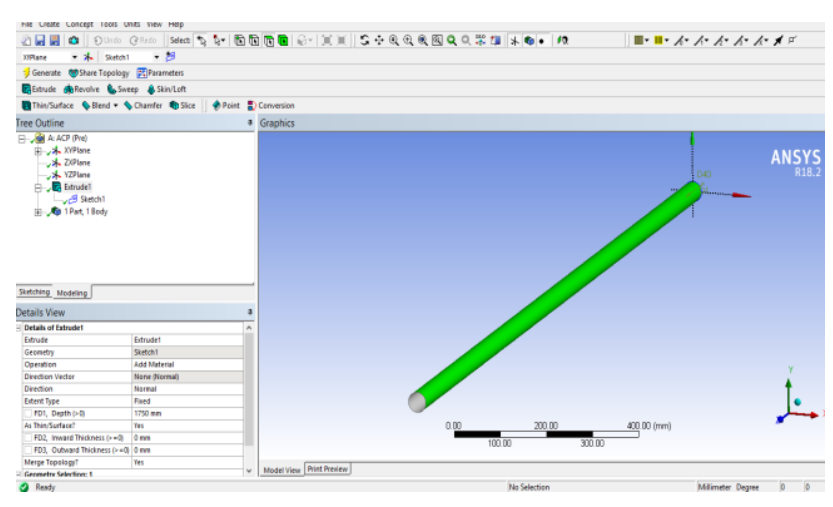

Figure 8 dimensions of shaft

\section{Boundary Condition}

\section{Define Boundary conditions:-}

One end of the transmission shaft is fixed to a shaft connected to the gearbox. Therefore, all degrees of freedom are stopped for this purpose, as shown in Figure 4.9. Another end of the shaft is connected to the differential shaft. When the gimbal is subjected to a torque (2030 Nm), a moment is applied around the $\mathrm{Z}$ axis, as shown in the figure.

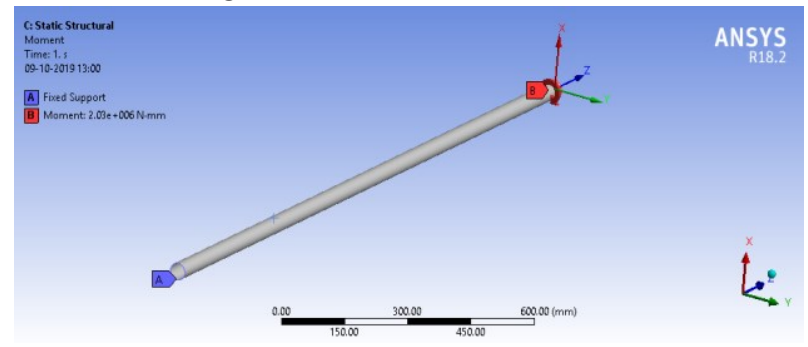

Figure 9: Define boundary conditions
In this study two material used for analysis

\section{Carbon HM and Carbon low density fiber}

\section{Validation:-}

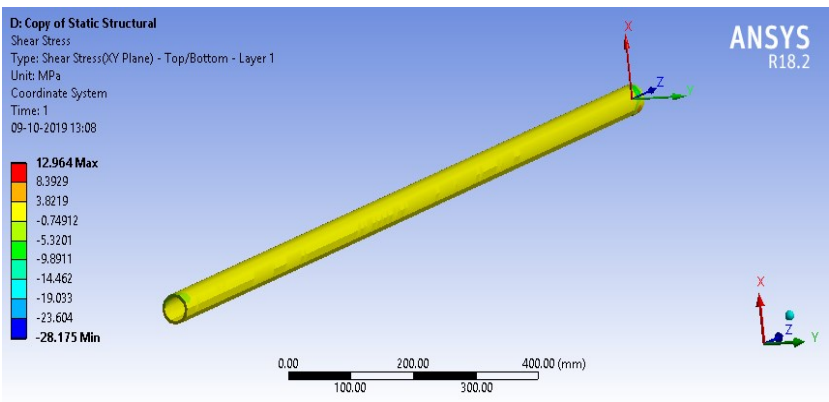

Figure 10: Top layer-1 shear stress value

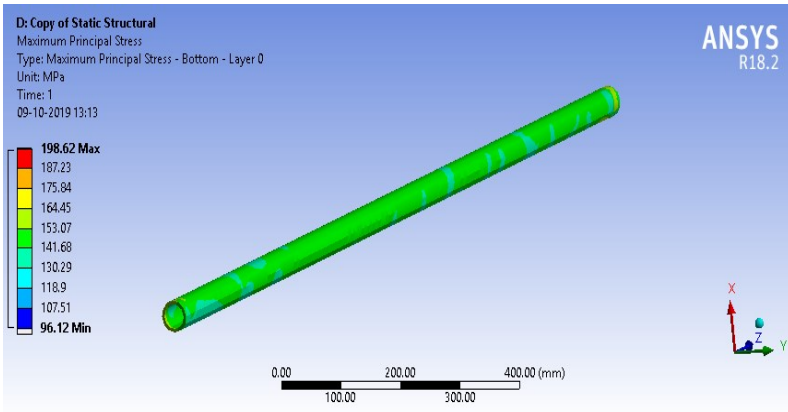

Figure 11 Equivalent stress

\section{Case-2 New material analysis :-}

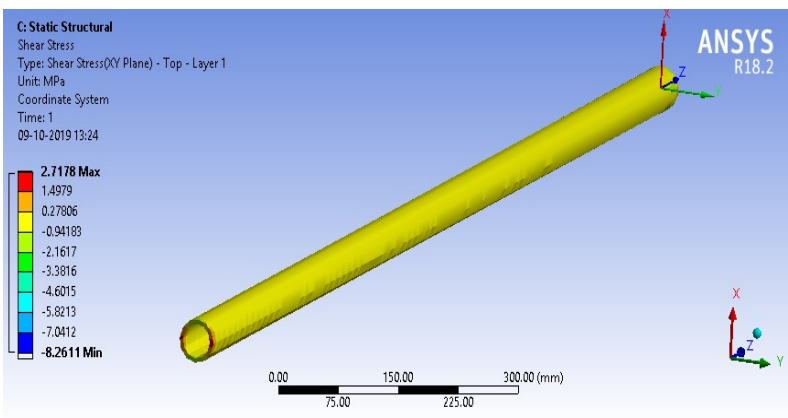

Figure 12 Top layer-1 shear stress value 


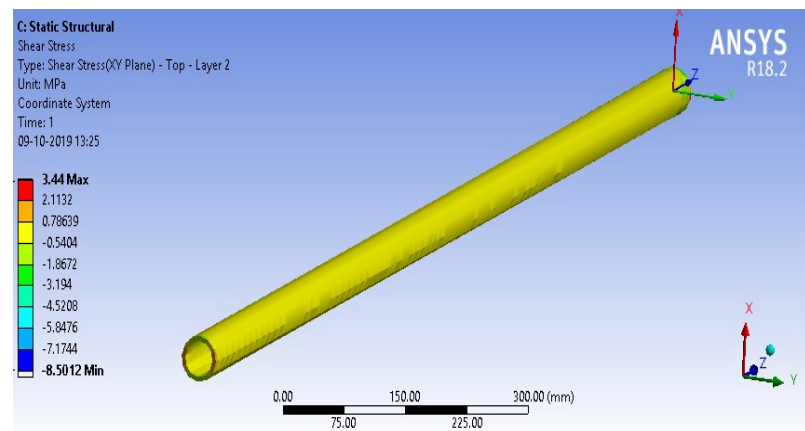

Figure 13 Top layer-2 shear stress value

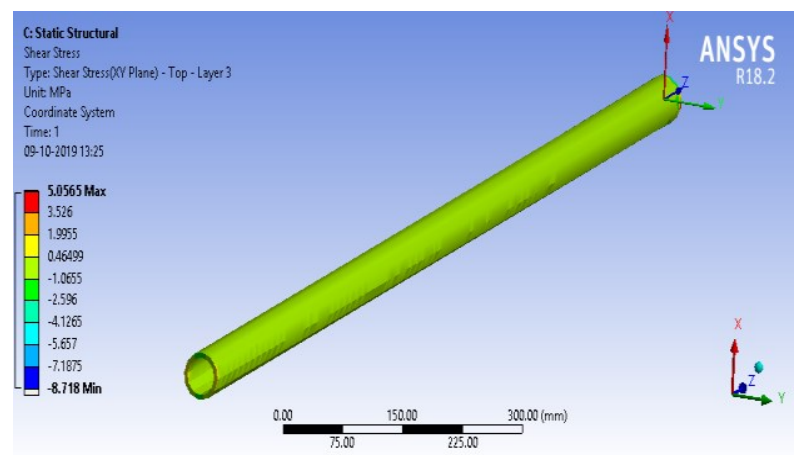

Figure 14 Top layer 3 shear stress value

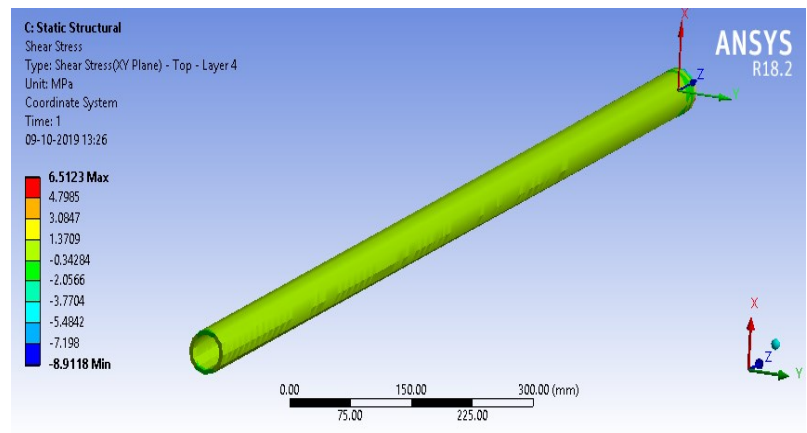

Figure 15: Top layer 4 shear stress value

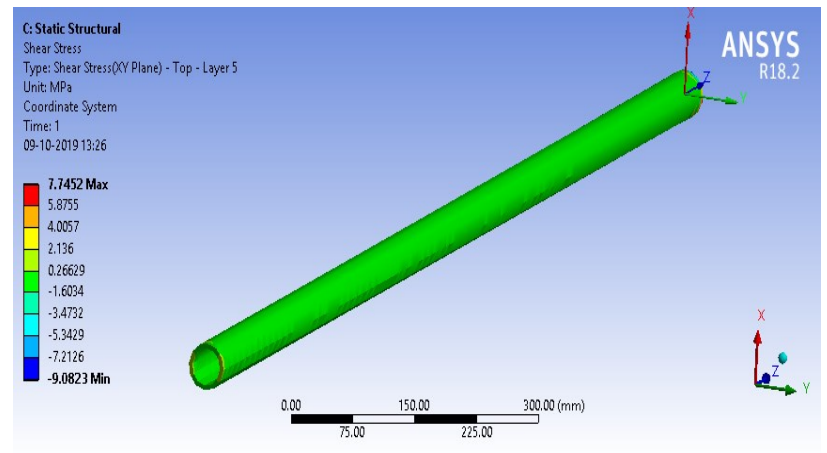

Figure 16 Top layer 5 shear stress value

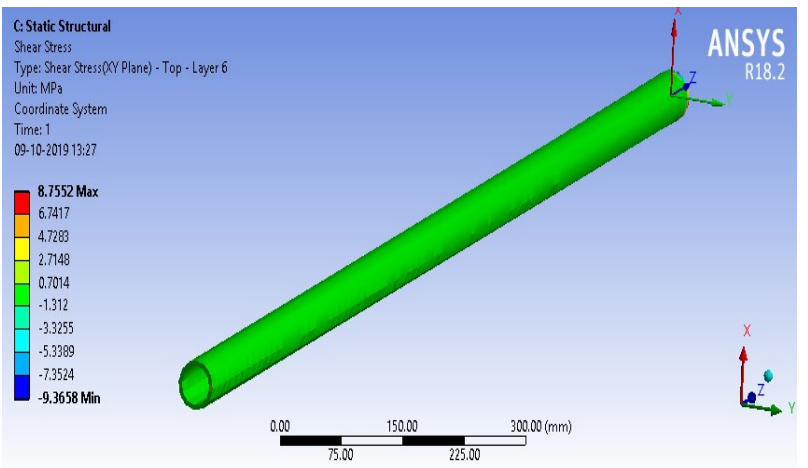

Figure 17 Top layer 6 shear stress value

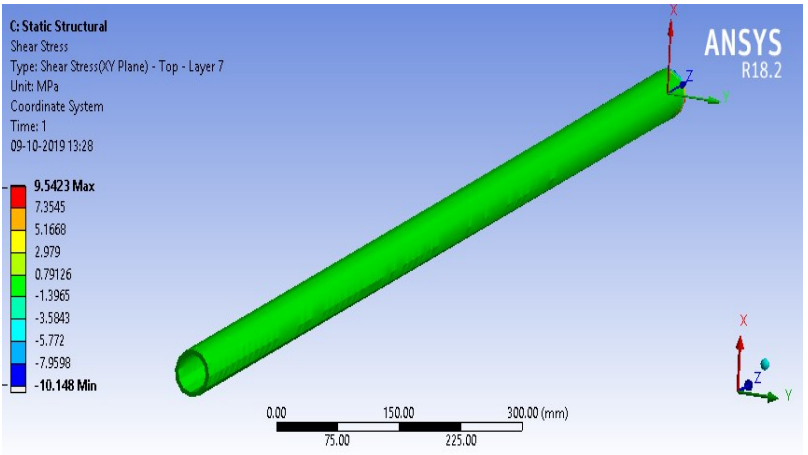

Figure 18 Top layer 7 shear stress value

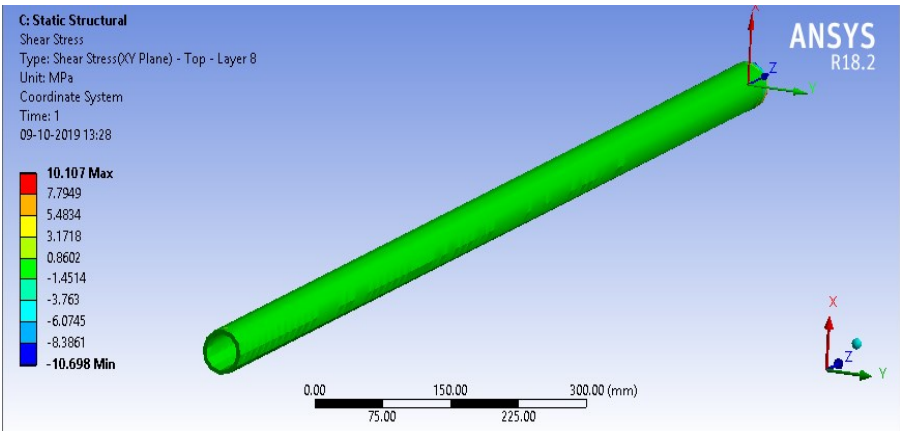

Figure 19 Top layer 8 shear stress value

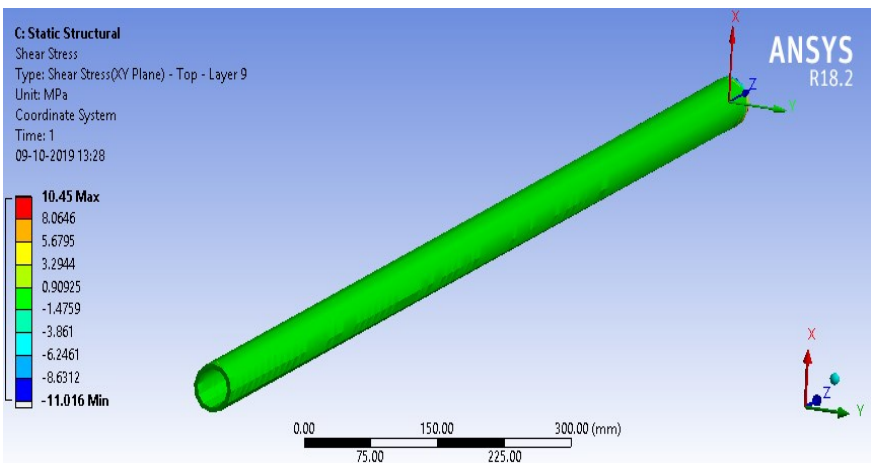

Figure 20 Top layer 9 shear stress value 


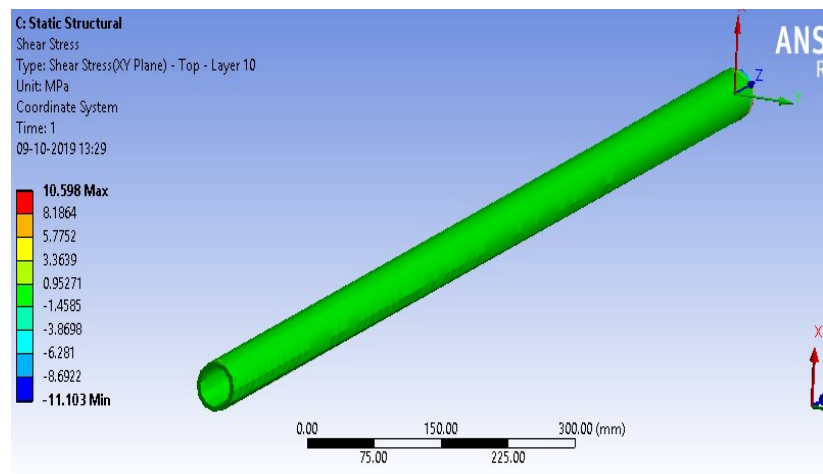

Figure 21 Top layer 10 shear stress value

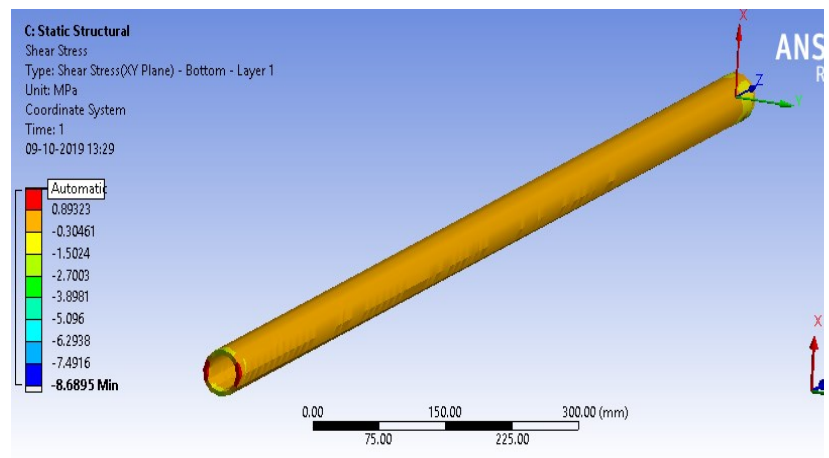

Figure 22 Bottom layer 1 shear stress value

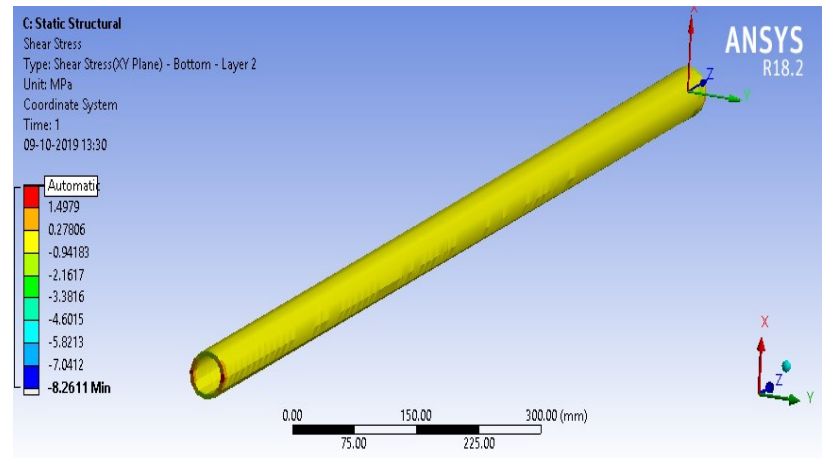

Figure 23 Bottom layer 2 shear stress value

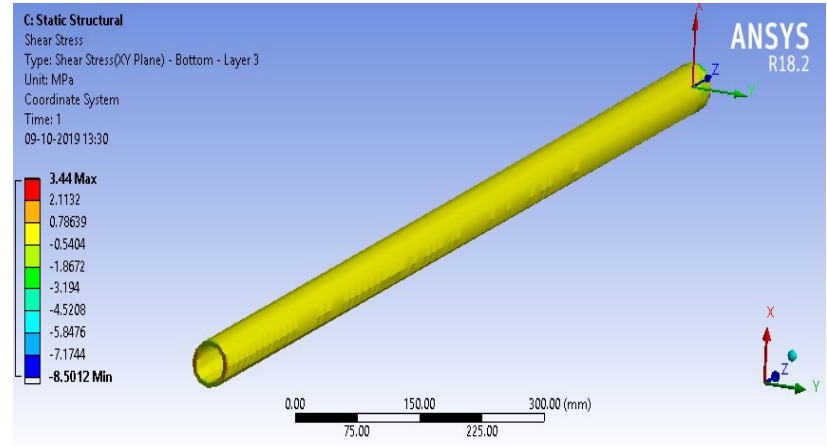

Figure 24 Bottom layer 3 shear stress value

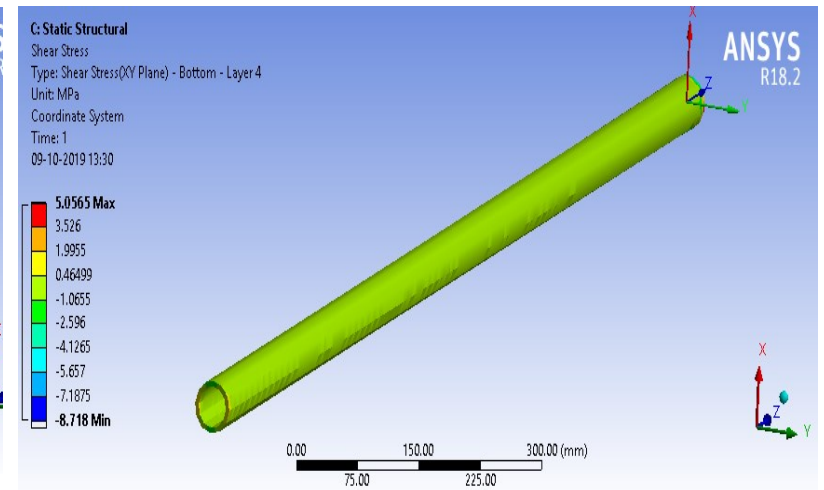

Figure 25 Bottom layer 4 shear stress value

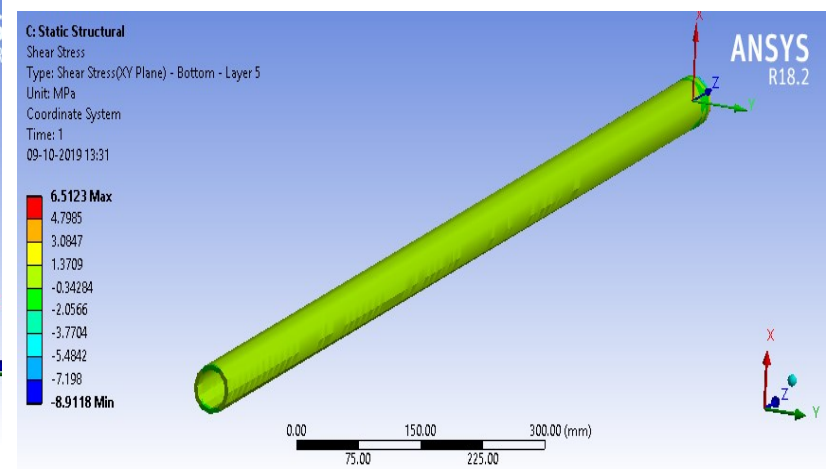

Figure 26 Bottom layer 5 shear stress value

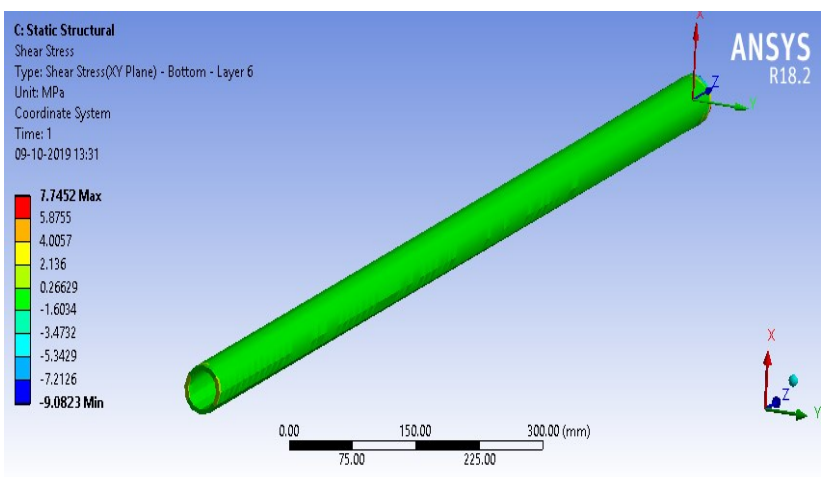

Figure 27 Bottom layer 6 shear stress value

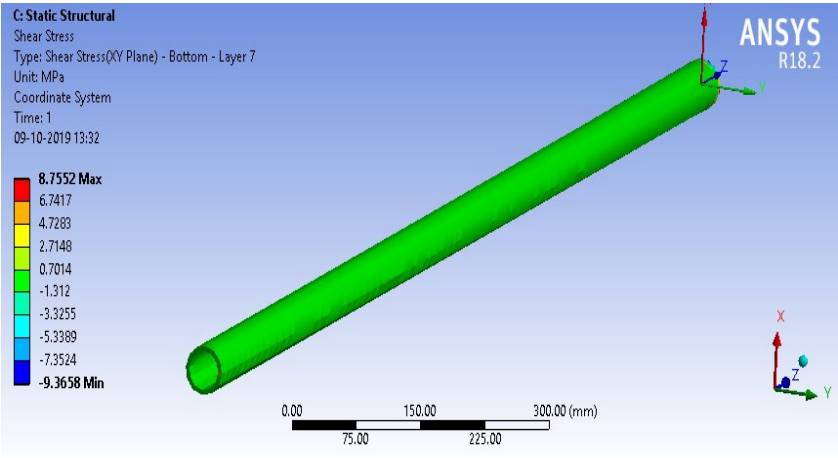


Figure 28 Bottom layer 7 shear stress value

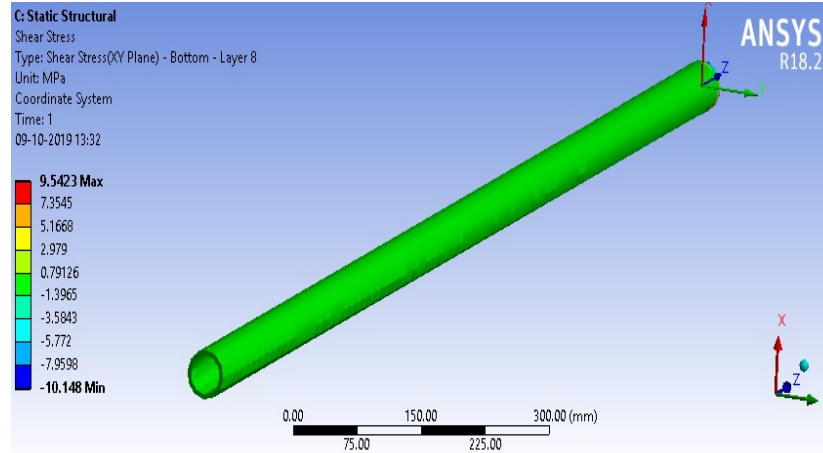

Figure 29 Bottom layer 8 shear stress value

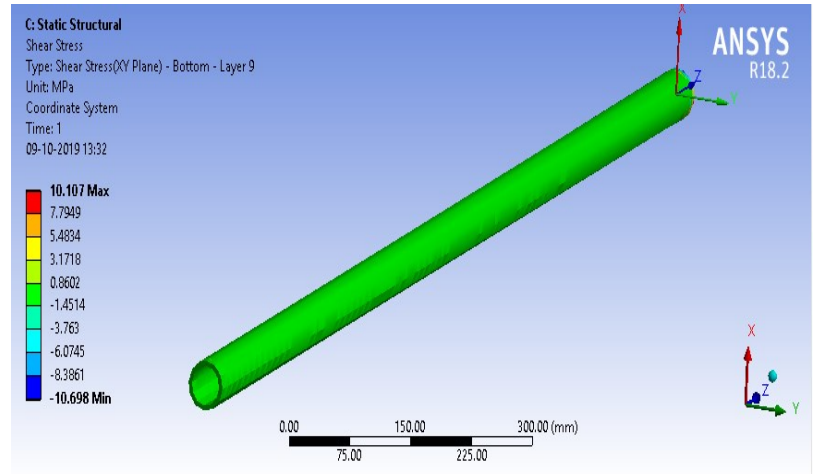

Figure 30 Bottom layer 9 shear stress value

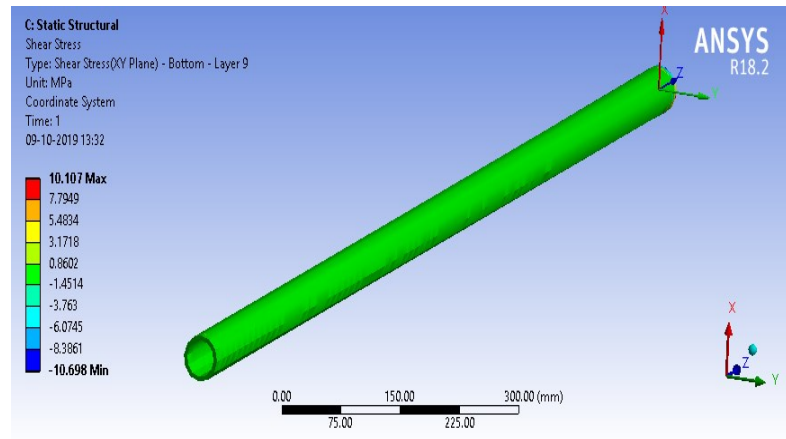

Figure 31 Bottom layer 10 shear stress value

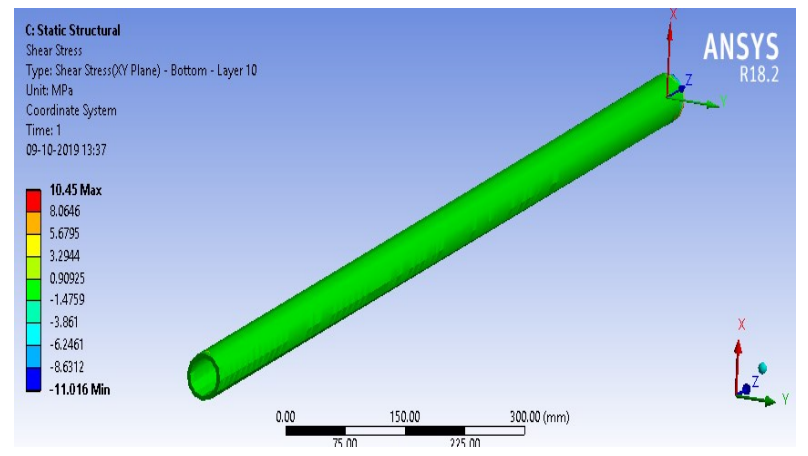

Figure 32 Bottom layer 10 shear stress value

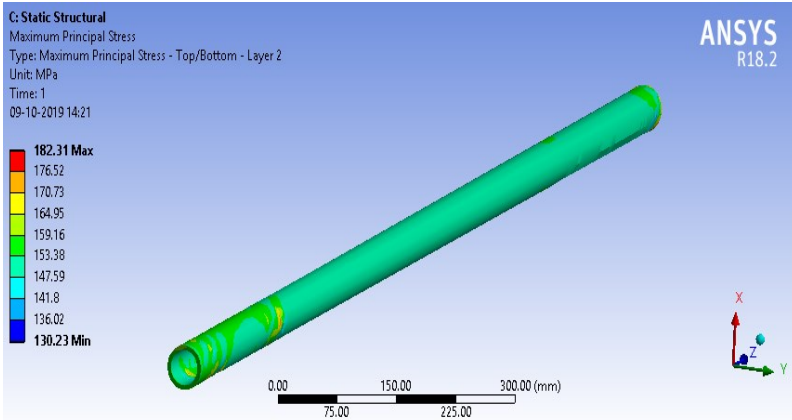

Figure 33 Equivalent stress

\section{Modal analysis case-2 :-}

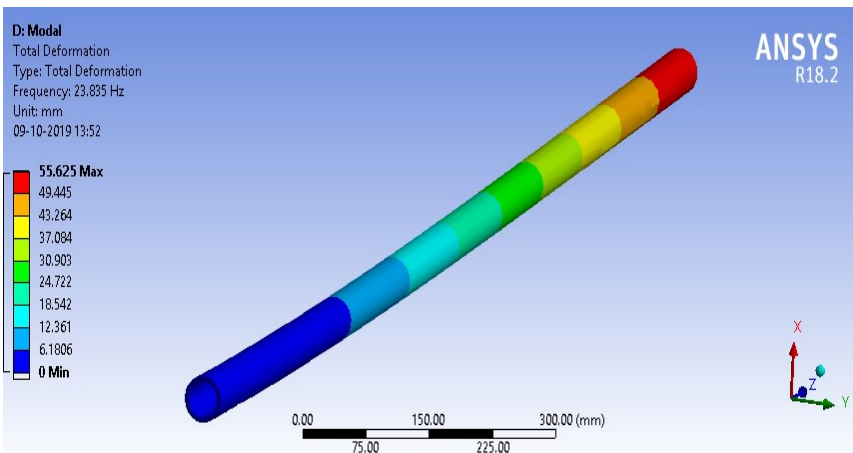

Figure 34 Total deformations at frequency $23.835 \mathrm{~Hz}$

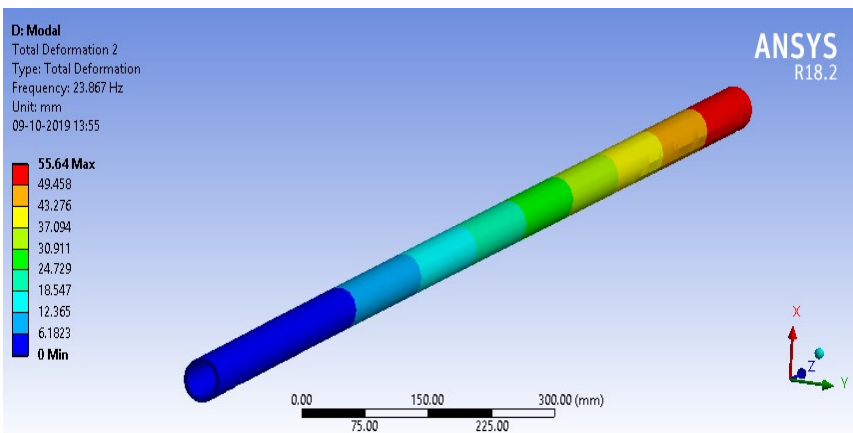

Figure 35 Total deformations at frequency $23.835 \mathrm{~Hz}$

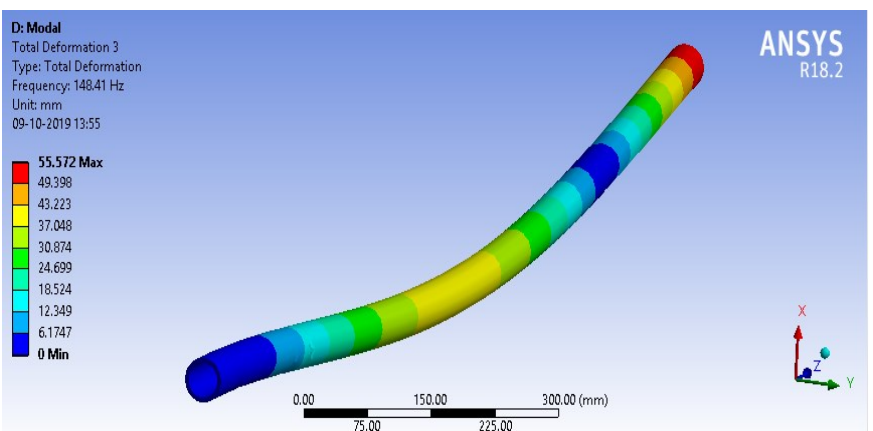


Figure 36 Total deformations at frequency $148.41 \mathrm{~Hz}$

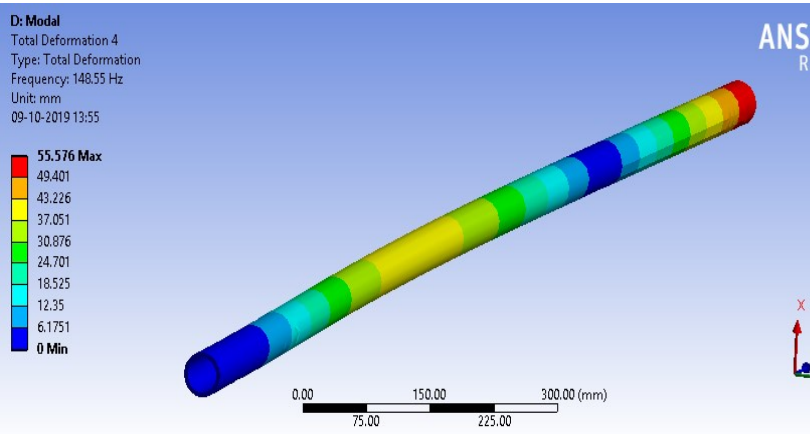

Figure 37 Total deformations at frequency $148.55 \mathrm{~Hz}$

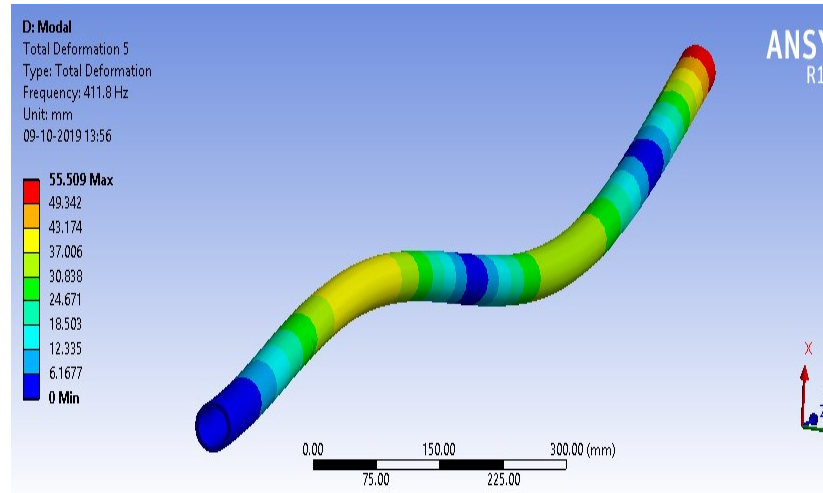

Figure 38 Total deformations at frequency $411.8 \mathrm{~Hz}$

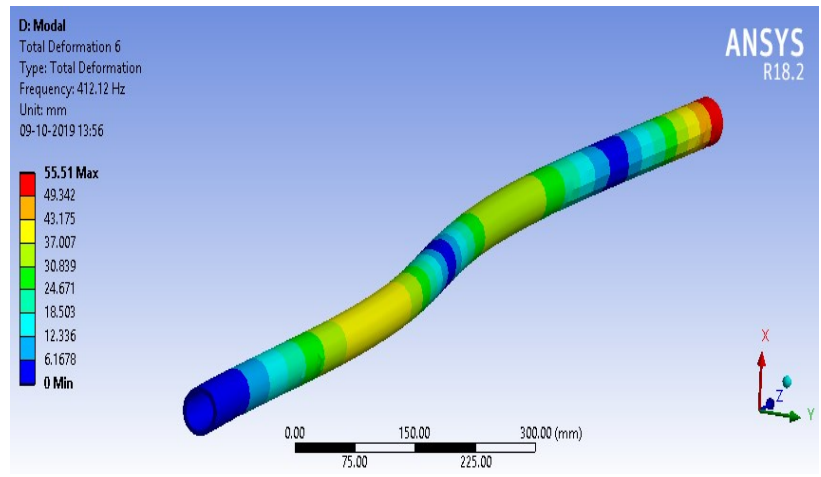

Figure 39 Total deformation at frequency $412.12 \mathrm{~Hz}$

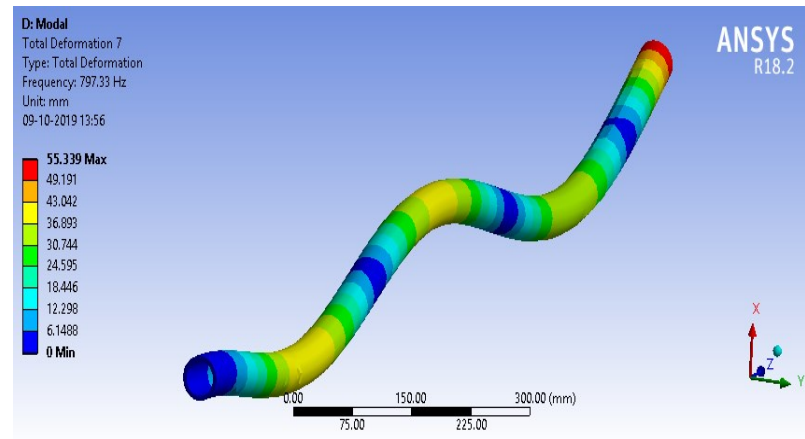

www.ijoscience.com
Figure 40 Total deformation at frequency $797.33 \mathrm{~Hz}$

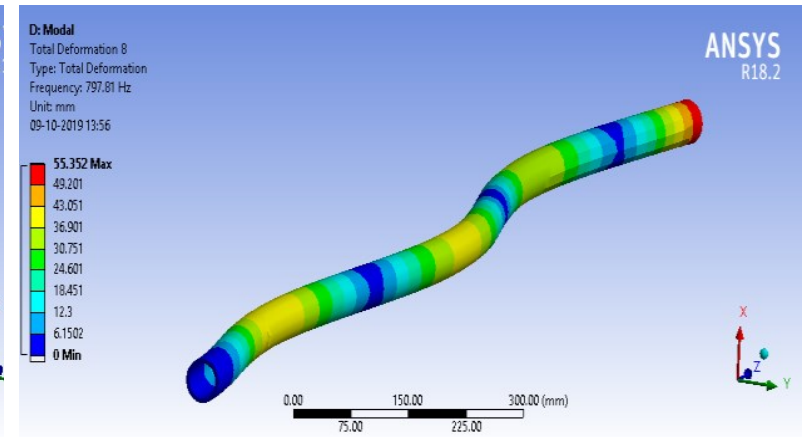

Figure 41 Total deformation at frequency $797.81 \mathrm{~Hz}$

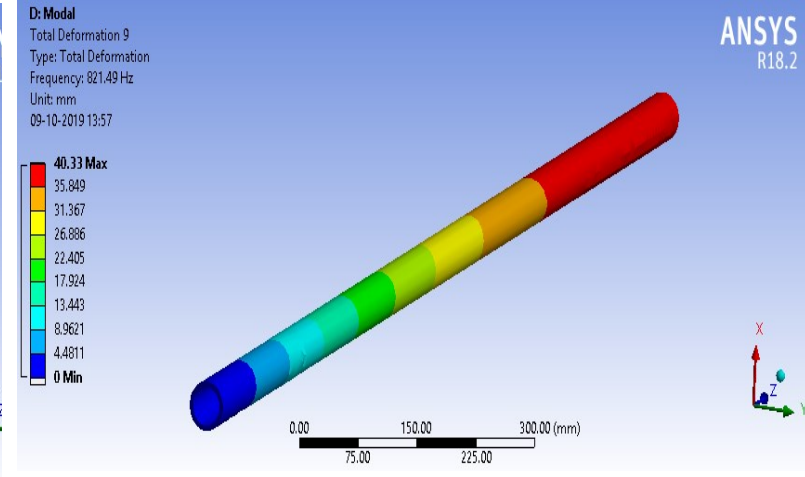

Figure 42 Total deformation at frequency $821.49 \mathrm{~Hz}$

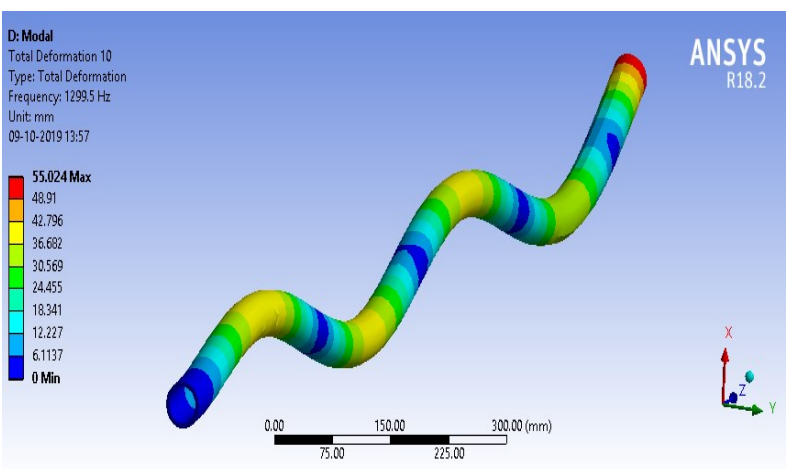

Figure 43 Total deformation at frequency $1299.5 \mathrm{~Hz}$

\section{[4] BUCKLING ANALYSIS}

Advanced composites seem ideal for applications on long transmission shafts. Their elastic properties can be adjusted to increase the torque they can carry and the speed with which they work. For thin-walled shafts, the failure mode below the applied torque is a greater torsional deformation than a material failure. 


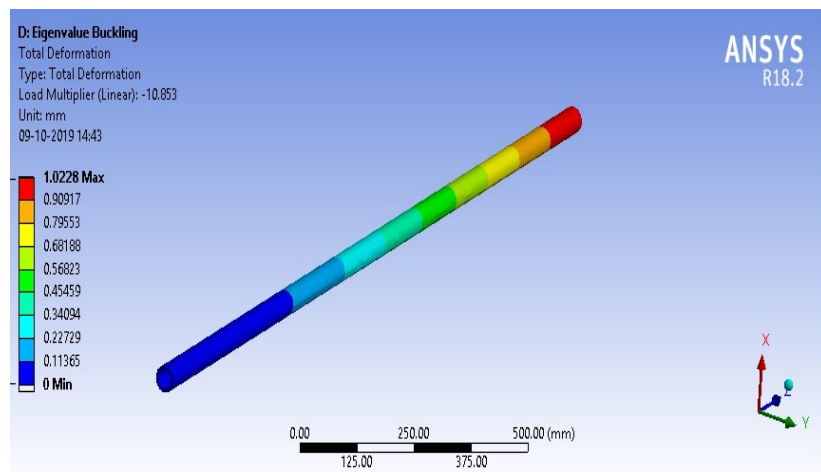

Figure 44 Total deformation

\section{FEA ANALYSIS ON AUTOMOTIVE COMPOSITE PROPELLER SHAFT}

\section{Maximum shear stress in layers}

Table 1: Results of static analysis for carbon $\&$ base paper material

\begin{tabular}{|l|l|l|}
\hline layer & $\begin{array}{l}\text { Carbon fiber } \\
\text { (New material })\end{array}$ & Base Paper \\
\hline Top-1 & 2.718 & 13.03 \\
\hline Bottom-1 & 2.0 & 12.6 \\
\hline Top-2 & 3.44 & 0.131 \\
\hline Bottom-2 & 2.718 & 0.127 \\
\hline Top-3 & 5.0565 & -0.139 \\
\hline Bottom-3 & 3.44 & -0.132 \\
\hline Top-4 & 6.5123 & 6.91 \\
\hline Bottom-4 & 5.065 & 6.78 \\
\hline Top-5 & 7.7452 & 6.832 \\
\hline Bottom-5 & 6.5123 & 6.64 \\
\hline Top-6 & 87552 & 7.01 \\
\hline Bottom-6 & 7.74 & 6.882 \\
\hline Top-7 & 9.523 & 7.39 \\
\hline Bottom-7 & 8.7552 & 7.317 \\
\hline Top-8 & 10.107 & -0.186 \\
\hline Bottom-8 & 9.5423 & -0.181 \\
\hline Top-9 & 10.45 & 0.191 \\
\hline Bottom-9 & 10.107 & 0.186 \\
\hline Top-10 & 10.598 & 15.3 \\
\hline Bottom-10 & 10.45 & 14.75 \\
\hline Weight & $2.6 \mathrm{~kg}$ & $3.2 \mathrm{~kg}$ \\
\hline & & \\
\hline
\end{tabular}




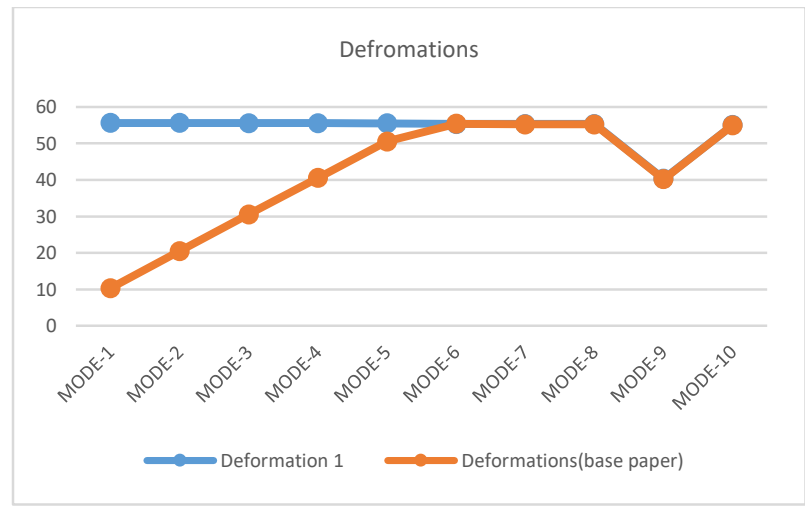

Graph 3: Natural frequency graph

\section{CONCLUSION}

1. The total weight of carbon fiber shaft is reduce. The total weight of the carbon fiber shaft is $2.6 \mathrm{~kg}$ is less then to previous study material.

2. The maximum stress obtained in the shaft is $182 \mathrm{Mpa}$ is lower than pervious result.

3. The share stress value in top first layer is $2.718 \mathrm{~mm}$ and top final layer $10.598 \mathrm{~mm}$, and bottom layer share stress value maximum value $10.45 \mathrm{~mm}$ and minimum value $2.0 . \mathrm{mm}$.

4. The stresses and displacement amplitudes of propeller shafts are reaching maximum values at the frequency, which are far away from the operating frequency range.

5. The tensional buckling load is higher (nearly 5 times) than the ultimate torque transmission by the shaft, so it is safer.

\section{REFERENCES}

[1] D Sarath Kumar, BalakrishnanSeeni "Composites as Drive Shaft using FEA” DOI: 10.15680/IJIRSET.2017.0612106 January 2018.

[2] B.James Prasad Rao, D.V.Srikanth "Design and analysis of automotive composite propeller shaft using fea" Volume 3, Issue 10, Part B, 2016, Pages 3673-3679.

[3] Mohammad Reza Khoshravan , Amin Paykani "Design And Modal Analysis Of Composite Drive Shaft For Automotive Application" International Journal of Engineering Science and Technology (IJEST) April 2011.

[4] Dattatray S. Ghorpade, Kishor B. Kale "Design and Analysis of Composite Propeller Shaft for Automotive Application" International Engineering Research Journal (IERJ) Special Issue 2 Page 4534-4540, 2015, ISSN 2395-1621.

[5] Sagar R Dharmadhikari, Sachin G Mahakalkar "Design and Analysis of Composite Drive Shaft using ANSYS and Genetic Algorithm - A Critical Review" Vol.3, Issue.1, pp-490-496 ISSN: 2249-6645 Jan-Feb. 2013.

[6] S. Mohan, M. Vinoth "Design and Analysis of Composite Drive Shaft for Automotive Application" DOI: 10.5829/idosi.mejsr. 2016.24. RIETMA118 2016

[7] RaffiMohammed ,K.N.D.Malleswara Rao "Modeling and Analysis of Drive Shaft Assembly Using FEA" Volume 8, Issue 2
,PP. 62-66 August 2013.

[8] Pankaj K. Hatwar, Dr. R.S. Dalu "Design and Analysis of Composite Drive Shaft" Index Copernicus Value (2013): 6.14 | Impact Factor: 4.4382013.

[9] Parshuram D, Sunil Mangsetty "Design and Analysis of Composite/Hybrid Drive Shaft for Automotive" ISSN: 2319 1813 ISBN: 2319 - 1805 Volume 2 Issue 01 Pages 160-171. 2013.

[10] J.Vinay Kumar, Dr. B. Omprakash "Modeling and Analysis of Composite Propeller Shaft" Volume - 02, Issue - 11, November 2017, PP - 24-28. 